\title{
Iron and Steel Technology in Japan-Progress in Post War Period and Its Future*
}

\section{By Shin-ichi NAGASHIMA**}

\section{Introduction}

Tracing back the activities of Japanese iron and steel industry to 1946 , the year immediately following the termination of the Second World War, the crude steel output was $560000 \mathrm{t}$. This figure meant $7.3 \%$ of $7650000 \mathrm{t}$, the output of 1943, when the industry recorded the maximum output in the previous period. From the above it is not difficult to see that the Japanese iron and steel industry felt a disastrous damage during the war. In spite of the effects of the war, the industry was able to achieve a rapid growth subsequently. The crude steel output in Japan exceeded that of U.K. in 1961 and F.R. Germany in 1965. In 1973 the industry recorded an outstanding figure of 120 million $t$, overcoming the wall of 100 million $t$ and ranked as the third in the world following U.S.A. and U.S.S.R. in the crude steel output. (See Fig. 1.)

Along with the increase of output, the Japanese iron and steel exports increased year by year as shown in Fig. 2. In 1974 the Japanese industry attained $26 \%$ of market share in the world and since then has been playing an important role in world economic activities as the second largest steel exporter following European Community (EC).

The vigorous production activities of the industry reached the maximum point in the fall of 1974 . But the output has been decreasing since then reflecting the change in world economic climate. In the fall of 1973 the world experienced Oil Crisis. International conditions of resources, energy and other materials changed rapidly. The age of high economic growth rate was taken over by the age of low economic growth rate. The world economy fell into recession.

Although the circumstances and conditions the Japanese iron and steel industry is placed in today are no longer the same as those of the age of high growth rate, it is meaningful for us to review what were the reasons behind the miraculous progress the industry achieved in the recent 30 years and I will try this in this paper. The subject has been examined and analyzed from various points of view by many circles both inside and outside of Japan. To summarize these studies, the Japanese iron and steel industry was fortunately placed in such economic circumstances and at such a time as domestic demands for iron and steel were growing and was able to respond to such demands effectively and positively. To explain this point more in detail, the industry received benefits of following favorable factors.
(1) Japanese Government actively persued the policy to promote high economic growth with principal emphasis on development of heavy and chemical industries.

(2) Domestic and foreign markets of iron and steel were developed to support such governmental policy.

(3) The industry made active investment in most advanced equipment.

(4) There was rapid and significant progress in production technology.

(5) Good quality fuel was available from various parts of the world at low price.

(6) An abundant labor force with high level of education was also available.

Thus, the industry, surrounded by growing demands for iron and steel made active equipment investment one after another to increase the output to satisfy the increasing demands. Along with the quantitative growth, the industry made outstanding achievement in the development of manufacturing technology. The technological development in the Japanese iron and steel industry will be reviewed in the following.

\section{Progress of Iron and Steel Technology}

The technological development of the Japanese iron and steel industry in the post war period was achieved principally in such fields as employment of large size blast furnace, oxygen blowing converter process (LD converter), continuous casting equipment, automatic, continuous and high speed rolling process, continuous processing in heat treatment (plate quenching and continuous annealing of sheets), and establishment of a series of computer control systems such as computer control of entire plant operation.

A comprehensive production system combining large size blast furnace and LD converter as major production facilities has been employed by Japanese steel plants actively. The popularity of this system owed to the factor relating to the supply of raw materials. Comparing with the pre-war period, the industry had no prospect for the continuous and steady supply of low-priced iron and steel scrap from the United States or pig iron from India. Under these circumstances, the open hearth furnace steelmaking method offered little merit. The industry had to supply inexpensive pig iron by itself operating own blast furnaces. As materials for iron were scarce in

\footnotetext{
* Originally published in Tetsu-to-Hagané, 65 (1979), 1264, in Japanese. English version received August 30, 1979.

** Professor, Faculty of Engineering, Yokohama University, Tokiwadai, Hodogaya-ku, Yokohama 240. Former Chairman of Editorial Committe, ISIJ.
} 


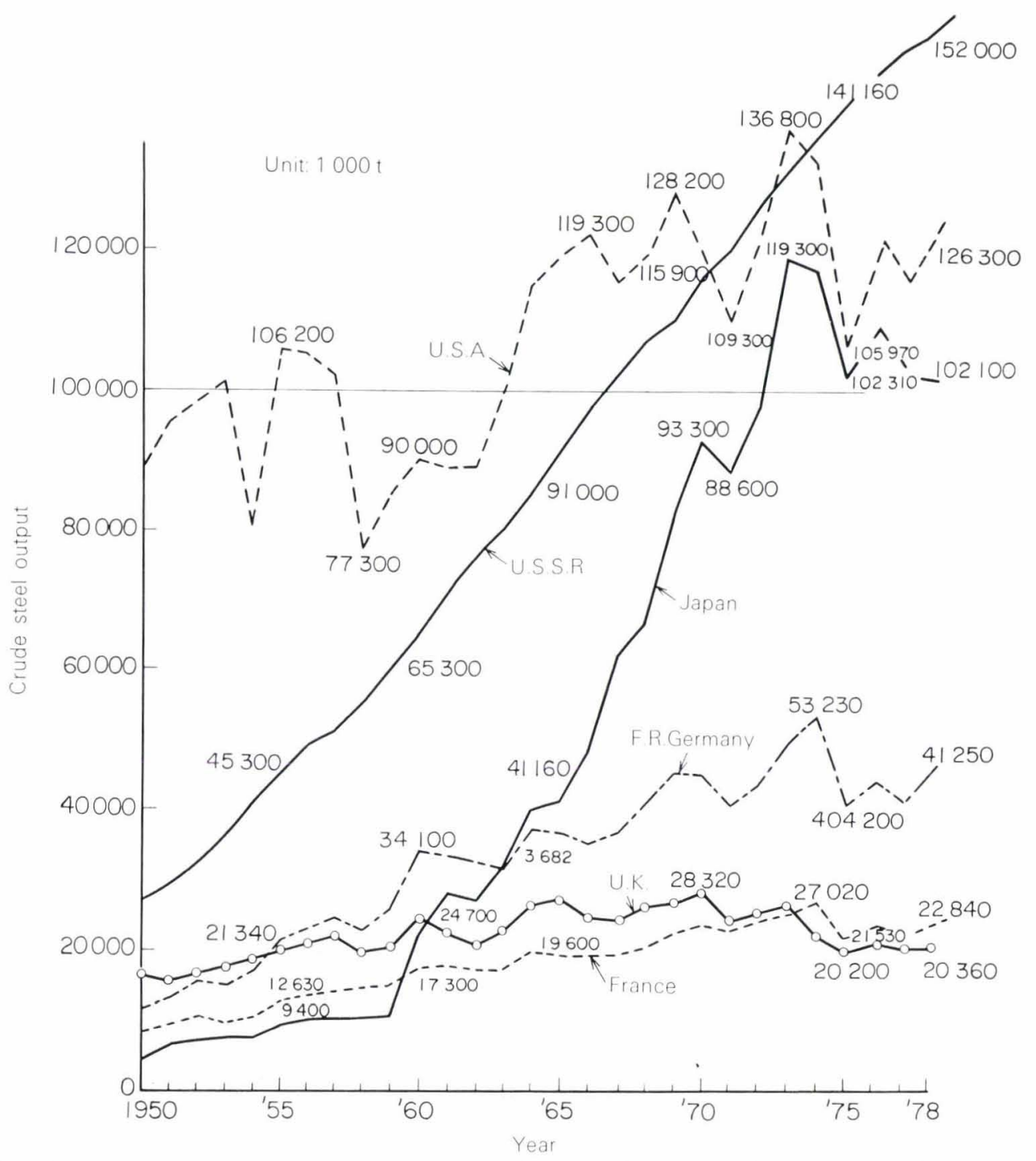

Fig. 1. Crude steel output of major steel manufacturing countries. (from Iron and Steel Statistics, ed. by Japan Federation of Iron and Steel)

Japan, the industry depended largely on foreign markets. Efforts were made on securing the supply of inexpensive but good quality materials. One of such efforts included the establishment of the transportation system in which exclusive bulk carriers were used for low cost transportation of raw materials. Steel plants were constructed around ports with highly efficient facilities to accept such bulk carriers, too.

While making the above-mentioned efforts to reduce transportation cost, the industry also made concerted efforts in researches related to pre-treatment technology for raw materials to realize utilization of less expensive but low quality iron ores as well as blast furnace technology including reduction of coke ratio for economic use of expensive coal.

At the time the Japanese industry was making the above-mentioned efforts, in Austria, the birth place of iron and steel industry in Europe, LD converter method became practically applicable for industrial purpose. The method proved advantageous in improving production efficiency and it required less scrap comparing with the conventional open hearth furnace method. The latter feature offered a complimentary advantage to the blast furnace method which could supply a large volume of inexpensive pig iron. Thus the iron and steel plants began to utilize the process combining these two methods.

In industries requiring heavy mechanical facilities, in general, the larger the size of facilities is the less the production cost is. Considering this factor, the Japanese steel industry made positive efforts for enlargement of blast furnace, steelmaking and rolling facilities and improvement of their efficiency. The scale of steel plants was expanded also. Such trend for large plant appeared first in 1952 when Yawata Iron and Steel Co., Ltd. constructed Yawata Works with $1360000 \mathrm{t} /$ year capacity. In 1967 the company expanded the capacity of the same plant to 10000000 t, and in 1975 Nippon Kokan K. K. constructed Fukuyama Works with 16000000 t/year capacity. Thus the industry sought for the scale merit and expanded the size of each manufacturing facilities as well as the entire plant.

The rapid progress in crude steel production activities was manifested in the expansion of facilities on one hand and improvement in work procedures and technology of iron and steel engineers who were responsible for the actual operation of these facilities on 


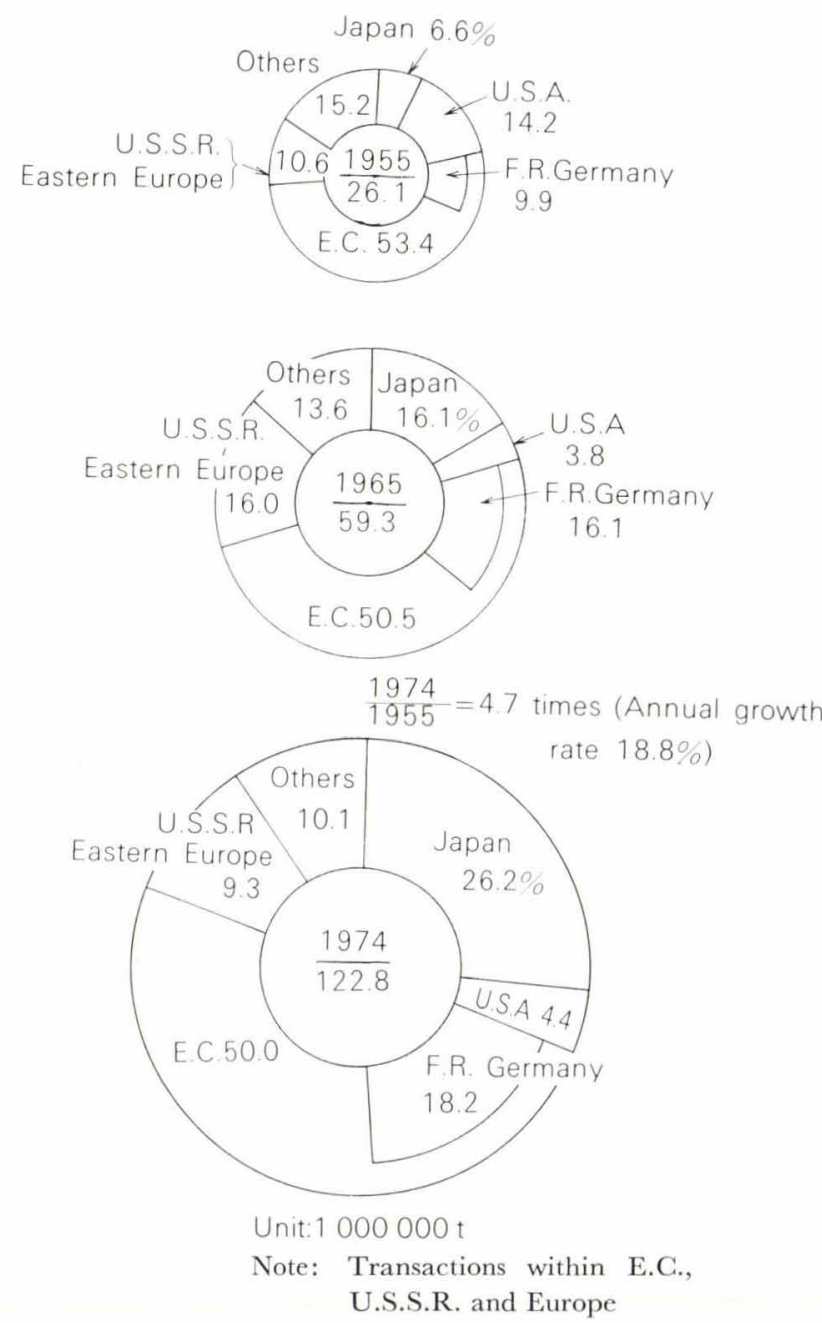

Fig. 2. Iron and steel export.

the other hand. Development in the fundamental and applied study on the science and technology of iron and steel contributed also for the advancement. The progress in such other related technology as industrial machinery production technology, refractories (development of new materials and application technology), oxygen manufacturing technology, and vacuum technology cannot be overlooked in this regard, too. However, attentions will be paid restrictively on the development of iron and steel technology in this paper.

\section{Ironmaking Technology}

In the field of ironmaking, there was the need for production of large volume of pig iron at low cost as previously mentioned. An emphasis was placed on measures relating to coking coal, pretreatment of row materials, enlargement of blast furnace and improvement in blast furnace operation technology as described more in detail in the following.

(1) Measures Relating to Coal (Economic Use of Low Volatile Coking Coal from U.S.A.)

1) Optimal blending of various kinds of coals

2) Pretreatment of coking coal

3) Manufacture of coke with briquette coal charge

4) Predehydration of coal and charging of pre- heated coal

5) Manufacture of formed coke

6) Technology to evaluate quality of coal and coke

(2) Pretreatment of Iron Orc

1) Sizing of iron ores - graining and sieving into 8 to $25 \mathrm{~mm}$ grains

2) Blending of iron ores to achieve uniform quality

3) Manufacture and employment of self-fluxing sinter using powder ore

4) Evaluation of quality and application technology of imported pellet

(3) Blast Furnace Operation Technology

1) Combination of blast technology-Oxygen enrichment in blast, high temperature humidity controlled blast, fuel injection

2) High top pressure and ultra high top pressure operation-employment of $1.0 \sim 1.5 \mathrm{~kg} / \mathrm{cm}^{2}$ to $2.5 \sim 3.0 \mathrm{~kg} / \mathrm{cm}^{2}$ as introduced from U.S.A. and U.S.S.R.

3) Stock line profile regulation-employment of movable armour

4) Increase of sinter and pellet ratio

5) Improvement in operation rate-tuyere breakage prevention measures

6) Promotion of measuring and controlling instruments and computer control

(4) Fundamental and Research on Ironmaking

1) Theoretical and experimental researches on gas flow distribution

2) Experimental research and theoretical research such as an introduction of mathematical simulation model of physical and chemical phenomena in the furnace

The introduction of varied types of technology, improving the plant operation works described above led to the increase in tapping rate and reduction of fuel ratio and coke ratio as shown in Fig. 3.

It is worth mentioning here that dissection tests of an actually operating blast furnace was carried out. For a long time the blast furnace had been considered as a black box with many questions. In order to make clear the physical and chemical phenomena in the blast furnace it is best to conduct the dissection test. But such experiment had been considered to be difficult because of the requirement of an enormous amount of expenses and personnel requirement for prolonged test operation, analysis and review. Nevertheless, the dream of blast furnace researches was realizde in 1968 when No. 5 B.F. $\left(646 \mathrm{~m}^{3}\right)$ of Higashida Works of Yawata Steel Co. was dissectioned for investigation. The B.F. practically operated until then was water-quenched for investigation. Similarly in 1970 No. 1 B.F. of Hirohata Works of Nippon Steel Corp. (1 $407 \mathrm{~m}^{3}$ ) was offered for the research also. From these investigations, following points were clarified.

1) Falling behavior of charged materials

2) Powderization of charged materials including iron ores

3) Recycling of alkali contents in charged materials 


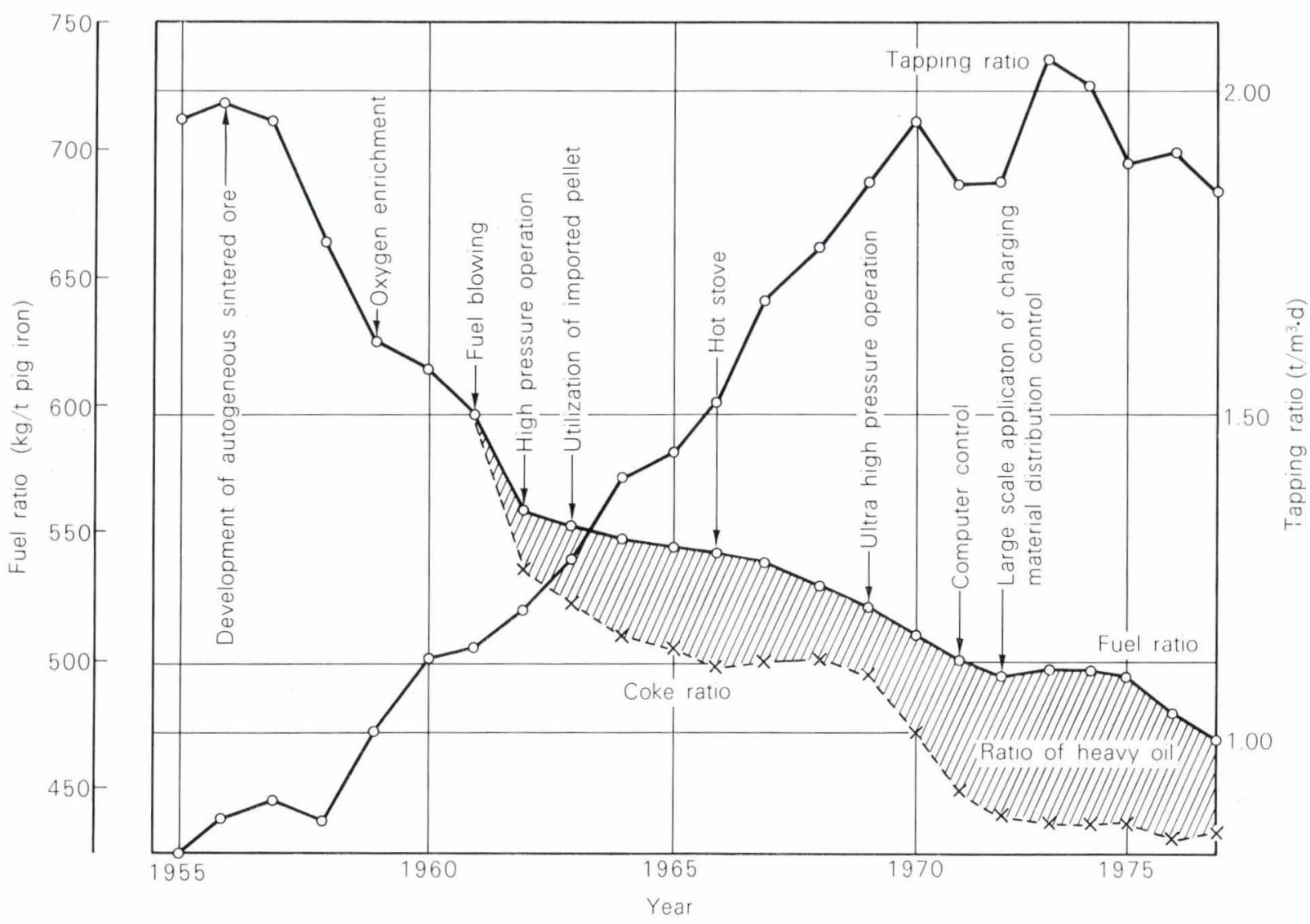

Fig. 3. Blast furnace operation record in Japan. (from Tetsu-to-Hagané, 61 (1975), No. 5, 443)

4) Permeability in softening, melting, and melting layers

5) Melting zone and furnace core

6) Temperature distribution and heat retention zone

7) Reduction process inside blast furnace

8) Pig iron formation process

9) Slag formation process

These blast furnace investigations presented numerous information on solid structure of inner furnace and reaction processes inside the blast furnace.

\section{Steelmaking Technology}

It has been mentioned that in 1973 the crude steel output in Japan increased to the level exceeding 100 million tons. Main reasons contributing for this outstanding achievement were the positive introduction of most advanced technology such as LD converter vacuum degassing and continuous casting methods and the high level of technological standard of engineers who made improvements in the newly introduced technology to create more advanced one. Such major achievements are explained below.

\section{BOF Process (Oxygen Top Blowing Method)}

\section{(1) Operation Technology}

Blowing and steelmaking time per charge was reduced gradually. Today the average blowing time is $12 \mathrm{~min}$ and steelmaking time is $28 \mathrm{~min}$. The mixing ratio of molten pig has been increasing and today $80 \%$ is the average ratio while the maximum ratio exceeds $90 \%$. Computer control was introduced to enable stable operation. At the initial period, such control was employed in static simulation model for control of the quality of oxygen blowing. Recently dynamic simulation model method such as data compilation relating to the volume of waste gas and its composition and terminal control by finding out temperature of melt steel during blowing and carbon content using sublance.

(2) Technology Relating to Furnace Body

Optimal blowing pattern, shape of multi-holed lance and optimal furnace body profile were determined trhough chemico-engineering and metallurgical experiments on blowing. With respect to the inner furnace volume, in 1957 the maximum volume was $50 \mathrm{t}$. Subsequently the volume was raised to $220 \mathrm{t}$ in 1968 and $300 \mathrm{t}$ in 1971. The desirable life of lining in the initial period was 400 charges or more. In 1963 the life was extended to 800 charges and by 19711500 to 3000 charges was the average life. Some plants have recorded the life exceeding 5000 to 10000 charges, too.

(3) Production of Steel of High Quality

Special steel and other high quality steels have been manufactured by electric furnace but studies are being conducted on the application of BOF process for melting of these high quality steels. Under these studies, the melting of steel with high carbon content, low alloy steel and stainless steel has been made successfully. Further by combining desulfurization of molten pig iron or vacuum degassing method, BOF process has become applicable for the production of 
steels with very low carbon content and low sulfur content, clean steel and steel with low hydrogen content.

\section{Electric Furnace Method}

As Heroult electric furnace method offers flexibility in operation and requires comparatively low equipment cost, the method is used not only for production of special steel but also for that of ordinary steel. The crude steel output in Japan by this method is $18 \%$ of total crude steel output.

Technological innovations in this field include following measures aimed at improvement of productivity.

1) Development of UHP (ultra high power) operation technology

2) Enlargement of inner volume

3) Employment of supplementary burner

4) Technology to minimize reduction period

5) Special melting method

Recently various severe demands have been raised on characteristics of steel and particularly on steel of high reliability. To satisfy such demands many studies have been conducted to discover an appropriate melting method or secondary refining method. The development of new methods for production of high quality steel is an important task. Studies conducted for this purpose include followings.

1) Electro slag remelting method (ESR method)

2) Vacuum induction melting method (VIM method)

3) Vacuum arc remelting method (VAR method)

4) Electronic beam melting method (EB method)

5) Prasma arc melting method (PAM method)

3. Secondary Refining Method and Ladle Refining Method

1) Desulfurization of molten pig iron-Removal of sulfur from steel can be made at any one of three stages of treatment of raw materials, ironmaking and steelmaking but is most effective at the stage of molten iron. Many desulfurization methods have been tried in this regard including (i) shaking ladle method, (ii) stirrer method, (iii) injection method, (iv) gas blowing and stirring method, (v) magnesium desulfurization method, and (vi) bubble pump recycling and stirring method.

2) Vacuum casting method includes (i) vacuum casting method (in restrictive meaning), (ii) ladle drop degassing method, and (iii) tapped steel dagassing method.

3) Vacuum pumping degassing method (DH method)

4) Vacuum recycling degassing method ( $\mathrm{RH}$ method)

5) Ladle stirring dagassing method includes (i) gas stirring method and (ii) electronic induction stirring method.

6) Arc heating ladle refining method includes (i) ASEA-SKF method and (ii) VAD method.

7) Vacuum decarburization method includes (i) VOD method and (ii) RH-OB method.

8) Argon oxygen decarburization method (AOD)
For production of high quality steel, these methods are considered as important as the special melting method previously mentioned.

\section{Ingotmaking Technology}

Major attention has been paid on surface separation of inclusion and enlargement of ingot as follows.

1) Porous prug technology

2) Hot top technology including (i) exothermic riser sleeve and insulation riser sleeve, (ii) antipiping compound agent, and (iii) covering compound for prevension of oxidation

3) Enlargement of steel ingots-Such ingots, as heavy as 17 to $18 \mathrm{t}$ for rimmed steel and $40 \mathrm{t}$ capped steel are available today, while killed ingot for rod steel is increased to 5 to $10 \mathrm{t}$.

4) Automatic injection through application of (i) auto pour, (ii) crane scale, and (iii) sliding nozzle.

\section{Continuous Casting Method}

The first continuous casting facilities introduced to Japan were put into operation in 1955. For 10 year up to 1965 a little attention was paid on installation of these facilities. There were only 8 units in the whole country. However, the number increased to 20 in 1968, 40 in 1970, and over 90 in 1973. As a result the ratio of continuously cast steel in total crude steel output increased from $4 \%$ in 1968 to $12 \%$ in $1971,20 \%$ in 1973, and $35 \%$ in 1977.

The period of slow growth of these facilities corresponded to the period when steel firms were examining the comparison of equipment cost and operation merits as well as operation ratio and quality of products. Subsequently steel firms began to study application of blooming and billet facilities for rod steel and continuous casting machine for large section slab for plates and sheets. Various technological improvements have been recorded since then, improvement in quality of cast steel, wider application of facilities and improvement in yield, for example. Major innovations consist of following.

(1) Improved yield due to improvement in casting speed, enforcement of cooling and improved operation rate with emphasis on establishment of stable operation conditions.

(2) Wider application including not only ordinary steel but also stainless steel, electro-magnetic silicon steel, low alloy steel and other killed steels and Riband steel. However, the method has not been successfully applied to rimmed steel yet.

(3) Improvement in quality through improvement in technology relating to surface crack, nonmetallic inclusions and inner segregation. The effective measure for the prevention of surface crack is employment of continuously cast powder, that for non-metallic inclusions is employment of argon bubbling and argon seal while electro-magnetic stirring is effective for prevention of central segregation.

\section{Other Technology}

\section{(1) Continuous Steelmaking Method}

Various organizations in the world have been studying to develop an effective method in this field. In Japan, National Research Institute for Metals of 
Science and Technology Agency is conducting a study to develop NRIM multi-stage steelmaking method.

(2) Oxygen Bottom Blowing Converter Method

Since the publication of a new bottom blowing converter method by Canadian researchers in 1965, various countries have been examining the possibilities of practical application of this method. In Japan, Kawasaki Steel Corp. introduced Q-BOP method of U.S.A. into its Chiba Works.

\section{Rolling Technology}

In the pre-war period, Japanese steel industry introduced a strip mill for U.S.A. even before their counterparts in Europe. During the post-war period, too, the industry imported the most advanced mills developed abroad to realize quantitative and qualitative progress. The industry conducted joint researches on rolling theory for a similar purpose. Through these studies, the industry found ways of automation and computer control of production processes. Innovations were made on following aspects.

\section{Rolling Theory}

1) Research on deformation resistance in plate rolling and establishment of mathematical simulation models

2) Analysis of overall characteristics of tandem rolling

3) Study of three-dimensional deformation theory on hole rolling

\section{Plate Rolling}

(1) Controlled rolling:

Establishment of hot rolling processes for improving of strength and toughness by fine-grained flat rolled products through appropriate pass schedule in hot rolling

(2) Continuous quenching:

Starting with application of dip quenching and press quenching methods, cooling pattern can be controlled by introduction of roller quench technology.

(3) Establishment of rolling method of continuously cast slab of obtaining excellent ductility applying lower forging ratio.

\section{Sheet Rolling}

(1) Hot rolling:

i) Employment of tandem mill and increase of rolling speed

ii) Shape control by roll bending apparatus

iii) Plate thickness control through automatic gauge control

iv) Control of coiling temperature through laminer water flow cooling

(2) Cold rolling:

i) Employment of tandem mill and increase of rolling speed

ii) Computer control of shape and plate thickness

iii) Research and development of rolling lubricants

iv) Study of oxygen washing method and establishment of pickling method using hydrochloric acid v) Double cold rolling method for tin plate

(3) Annealing technology:

i) Examination of optimal annealing cycle including reduction of annealing time in tight coil annealing

ii) Establishment of operation technology in open coil annealing

iii) Establishment and wider application of sheet continuous annealing technology

\section{Shape Rolling}

(1) Universal rolling method was introduced in 1960's later than in Europe.

i) About the rolling of $\mathrm{H}$-shape steels, the mathematical simulation model was applied extending the result of plate rolling method to three dimensional deformation processes.

ii) Tensile strength control in tandem rolling

iii) Continuous shape rolling

iv) Application of this technology to not only $\mathrm{H}$ shapes but also to rails, pile sheets, and angles

v) Computer control of rolling

(2) Improvement in cooling and adjustment method

5. Rolling of Rods and Wires

(1) Quality Improvement:

i) Development of on-line crack inspection technology in hot rolling

ii) Development of descaling

iii) High speed rolling

(2) Installation of stillmore mill and improvement of operation works

\section{Pipe Manufacturing}

(1) Seamless pipes manufacturing technology through introduction of an improvement on Mannesmann method

(2) Pipe manufacturing through extrusion:

i) Introduction of and technological improvment on Ugine-Sejournet method

ii) Manufacturing of pipes having different sections

(3) Establishment of cold forming method

(4) Introduction and development of pipe welding technology:

i) Electrically welded pipe manufacturing methed

ii) Improvement in welding technology

iii) progress in non-destructive inspection technology

(5) Improvement in large diameter pipe manufacturing technology.

\section{Steel Products}

Outstanding progress has been achieved in development of many kinds of steel. This progress was borne out of the need to satisfy varied and strict demands from users concerning properties and performance of material steel. Following developments were made in this regard:

(1) Improved strength and toughness:

Quench and tempered or as hot-rolled high tensile strength steels, that for line pipe, high yield point steels, super high strength steels, steels for low temperature use. 


\section{(2) Steels for high temperature:}

Heat resistant ferritic steel, heat resistant austenitic stainless steel, heat resistant alloy; especially steels for automobile exhaust gas treatment and for heat exchanger of atomic reactor are recently developed.

(3) Corrosion resistant and stainless steels :

Weather proof steel, salt water resistant steel, ferritic stainless steel, austenitic stainless steel, precipitation hardening stainless steel and dual-phase stainless steel

(4) Free cutting steels:

Lead and sulfur bearing free cutting steel, calcium free cutting steel, titanium free cutting steel and free cutting stain less steel

(5) Steel sheets with good formability:

Slow aging and non-aging sheets for deep drawing and super deep drawing sheets containing titanium

(6) Plate with good weldability:

High tensile strength plate with excellent weldability under large thermal input.

(7) In addition to the above, numerous types of material steel with different properties have been developed: Electro-magnetic silicon plate and various kinds of surface finished sheets are some of these examples.

\section{Background of Technological Progress}

Looking over the technological innovations in the iron and steel industry in Japan during the post-war period, first we cannot but get impressed by the fact that the newest and best technology has been applied to every field of production processes and products and that the facilities have been operated at the optimal conditions and the products so-produced are of the best quality at a given time.

Every single newly developed technology has been put into practical application at some plant or an another in Japan. The advanced technology and facilities were always the subjects of close examination and analysis so as to utilize their merits to the utmost degree as well as to develop still more advanced technology. The entire climate surrounding the iron and steel industry was comparable to that of the capital of music, Vienna. In Vienna, there was rich cultural heritage to appreciate music and musicians, students and music lovers gathered to enjoy and support good music with critical ears. Severe criticism and warm support to artistic works were indispensable for the birth of talented musicians great pieces of music. In Japan the rich soil developed gradually to support the progress of technology on iron and steel just as Vienna prepared itself for the flourish of music. ${ }^{2}$

Here I would like to attempt an analysis of the Japanese readiness for the technological progress in iron and steel industry from a perspective different from those of previous attempts.

\section{Japanese Reaction toward Foreign Culture}

In general, the Japanese people are said to show a following pattern of reactions toward new technology. At first, they feign to be unmindful, then they are impelled by curiosity followed by refusal and finally they assimilate it. ${ }^{3)}$ This pattern is recognized in the example of introduction of steam locomotive (SL). People in the Meiji Period looked with admiration at the first appearance of trains led by SL between Shinbashi and Yokohama, followed by a period when the people rejected the introduction of foreign-born vehicle in historical castle-centered towns and railways had to be constructed in suburban areas. SL had assililatd into the life of the Japanese people soon. Today at the age of super express the people look at SL with nostalgic feeling.

It is fair to assume that other foreign culture found solid acceptance in the Japanese society creating the above-mentioned reactions in the process of acceptance. Let us take the example of history of Buddhism in Japan. The religion was introduced to Japan in 533 A.D. at the reign of Emperor Kin'mei. The imperial family and Soga clan (one of the large clans at this reign) were converted to this faith. This led to political strife with Mononobe clan, followers of traditional Shintoism. At the period of such introduction of Buddhism, the common people showed no concern whatsoever. But they began to show interest and attention on charity works of Buddhist temples and followeres. This was followed by the period when they made their resistance and rejection known against heavy tax and labor for construction of "Kokubunji", state-established provincial temples. Subsequently Buddhism acquired more followers mainly through efforts of missionaries. Having been accepted by the people, the religion became a part of the life of the people and developed as original Japanese religion.

The reaction pattern of the Japanese toward Chinese characters and literature was somewhat different from the above-mentioned example. No evidence of strong rejection can be found in the history of introduction of Chinese literature and characters. First the Chinese characters were adopted as the official language of the Japanese court. Then the Japanese began to use Japanese pronounciation while retaining the Chinese structure and Chinese characters to write and read Japanese language. At the same time the Japanese invented a method to use some of Chinese characters as sonic symbols only without making use of their respective meanings. Further innovations were made until simplified hiragana came into practical usage. It is interesting to find that the Japanese recognized that characters have two functions, symbolizing sound and article and phenomena at the introduction of the Chinese characters and that they started to utilize both functions without placing emphasis on either of them. They made best use of both functions and developed an original written language consisting of Chinese characters and kana.

\section{Reaction toward Modern Iron and Steel Manufacturing Method}

The modern iron and steel manufacturing method was introduced to Japan at the end of Tokugawa period to satisfy the requirements of cannon manufac- 
turing for coast-defence. From 1850 to 1855 reflection furnaces were installed in Saga, Kagoshima, Nirayama and Mito. These furnaces were constructed by Japanese artisans with domestically available materials using technology explaind in Dutch literature.

The first Western style blast furnace was constructed in Kamaishi under direction of a samurai of the Nanbu clan called Takatō Ohshima. The furnace was put into operation in December 1857.

Just as in the case of introduction of Chinese characters, the new technology of iron and steel manufacturing was introduced to Japan without causing any negative reaction among the Japanese society. One of the reasons for this ready acceptance was that this technology was considered necessary for national defense. Another reason was that the conventional ironmaking method called Tatara method could not supply adequately for growing demands. The iron produced through Tatara method was used for such forged products as swords, farming tools, carpenters' tools, and cooking utensils and for such cast products as artistic articles for tea ceremony and household utensils. As the supply and demand for the conventionally available iron and steel was sufficient for nonmillitary purposed, the new demands for military purpose has to be supplied by the new production processes. Under these circumstances there was no competition between the traditional and foreign introduced technologies.

One more reason why the Japanese showed little rejection toward the introduction of modern iron and steel technology was that the Japanese historically held admiration toward iron and iron products. This heritage is recognized in the fact that one of three holy symbols of the Japanese throne is the sword, said to be given from sacred cloud of heaven, and that many mild steel sheets are found in ancient tombs. It is fair to assume that in the ancient period the sword and iron were regarded as treasures as precious as gold, silver, and copper.

The awe and admiration for iron and iron products held by the Japanese is easily detected by many anecdotes concerning training of sword artisans and transfer of the sword manufacturing skill as well as stories about sacredness of sword.

\section{Feudal System of Tokugawa Period and Technology $y^{5}$}

In examination of technological activities during 300 years of Tokugawa period (1603 1868), two influential factors should be mentioned first. One was that the feudal government prohibited manufacture of new tools and another was that a person must inherit the occupation of his ancestors.

Because of prohibition of invention of new tools, the household utensils commonly used at the end of Tokugawa period were not much different from those of the Muromachi period (1390 1480). Under this restrictive policy, the artisans had to be content with the manufacture of familiar items. But they found their satisfaction in making these items with better quality. It was not allowed to manufacture tools with new functions. The artisans concentrated their efforts in inventing tools which could be handled more easily, in other word, familiar items but with finer grace, performance and design. Low quality tools were no longer acceptable. Gradually there rose the climate to respect artistic skill and technology.

The fact that one's occupation was determined by the family heritage gave grave impact on this respect toward technology. The following story populary told explain such sentiment. A skilled artisan sprayed moisture on a surface of a flattened wooden sheets and stuck two pieces with no binder. Then nobody could separate them because of the perfect flatness of the sheets. The fact that such story was told from person to person show how much the common people in Japan admired the refined artisanship or workmanship.

It should be mentioned here also that during Tokugawa period illiteracy rate was comparatively low because there were established many terakoya schools for children, which were private elementary schools. At these schools, the children learned how to read, to write and to use abacus.

At Meiji Restoration, modern technology was introduced to Japan one after another. New equipment and machinery were imported. The persons who were given responsiblity for operation of these facilities were not restricted to samurai class. People at many sectors were already prepared to handle these new technological introduction. They had sufficient understanding and willingness to face the modern technology.

\section{Introduction of Technology after World War II and Role of Academic Organizations}

Immediately after World War II, Japanese iron and steel industry had to reestablish itself from the scratch. At that time the technical level in U.S.A. and European countries was far ahead of the Japanese technological standard. The Japanese industry showed enthusiasm over introduction of every available technology. As each firm imported these under its own development program, in many cases similar technologies were introduced overlappingly into different firms.

Nevertheless, these firms also were willing to conduct joint researches for problems common to them. Many research committees of Japan Society for the Promotion of Science including those on steelmaking, ironmaking and properties of steel, Joint Society on Iron and Steel Basic Research organized by the Japan Society for the Promotion of Science, Japan Institute of Metals and ISIJ as well as Joint Research Society of ISIJ presented opportunities for such cooperative undertakings. Researchers and engineers from private firms, public research institutes and academic organizations participated in the wide range research activities and information exchange of these societies.

ISIJ's Joint Research Society consists of 18 committes and 23 subcommittees conducting useful researches in varied fields covering ironmaking, steelmaking, coke, electric furnace, special steel, rolling theory, plates, wire rods, pipes, analysis, heat recovery, refractories, instrumentation, quality control, 
and facilities.

As an indication of iron and steel research activities in Japan, the increase in the number of papers presented at the Spring and Fall ISIJ Meetings is shown in Fig. 4. The number of papers presented each year shown in the figure indicates the sum of papers presented at annual lecture meeting and discussions sessions. Comparing these figures with the increase in membership, the papers increased proportionally to the increase in membership up to 1969. Starting in 1968, membership has not been increasing but rather show a decreasing tendency, while the number of papers is increasing with a high rate.

Table 1 shows the number of papers presented per year by 100 members. The rate of growth in recent years is truly a wonder. This clearly tells the conscientious attitude of the scientists and engineers of iron and steel toward the requirements of the industry surrounded by many economic and other restrictions.

The above fact also indicates the strong support the members hold on ISIJ Meetings as the place for announcement of reserch achievements, discussion and exchange of information. At the same time the above is a good evidence that ISIJ activities have been performaing an indispensable role in advancement of iron and steel technology.

\section{Future of Iron and Steel Technology of Japan}

Several excellent studies ${ }^{6-8}$ ) have been published

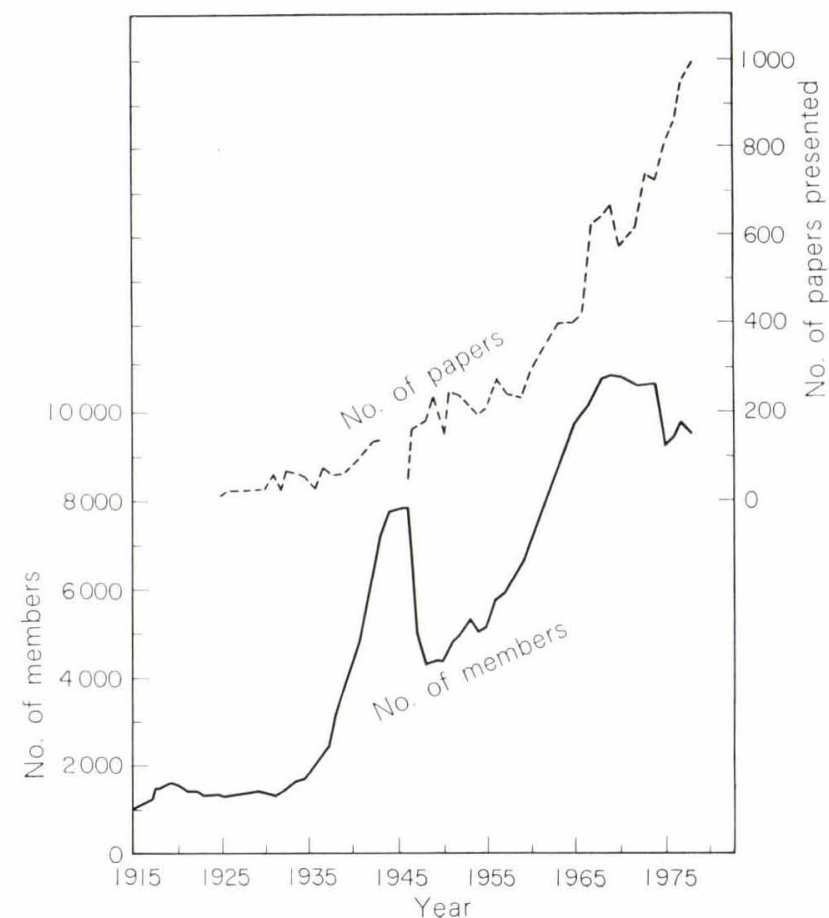

Fig. 4. Numbers of ISIJ members and papers presented by them. in connection with the direction the Japanese iron and steel industry may follow. I would like to present my view here by briefly repeating previously published opinions. ${ }^{9)}$

As earlier stated, the Japanese iron and steel industry depends on imports for the supply of majority of raw materials. Considering this fact, it is desirable to have close cooperative relations with the resources suppliers in the field of technology, too.

Apart from the above, the industry has following tasks of general nature.

1) Comprehensive review of iron and steelmaking processes

2) Review from the perspective of the users of steel

3) Review for economic use of unrecoverable resources such as fossil fuels and mineral resources

4) Review for recycles of resources and others

\section{Comprehensive Review of Iron and Steel making Processes}

It is expected that the raw materials available in the future will be of the lesser quality. On the other hand, the demands for material steel with superior performance will increase more and more while the prices cannot be raised extensively. The only possible answer for this dilemma is to review each production process and to determine the cost and quality of the product in consideration of subsequent and preceding processes.

For this purpose, following factors should be examined.

\section{Economy of an Entire Operation System}

The crude steel output today is regulated at $2 / 3$ of the capacity. This situation is expected to continue for some time and the efforts of an individual plant have already reached to the limit. Under these circumstances, it is necessary to examine which plant should perform primary production function in the production plan of an individual firm.

\section{Energy Conservation}

Steel firms have been making continuous efforts on this matter and their efforts seem to have reached the maximum limit. In the future it is necessary to carry out elimination of processes wherever possible following examples attempted by other industries as well as to promote utilization of high entropy energy resources.

\section{Continuous and Direct Processing}

Continuous processing has been promoted so extensively that only in such fields as continuous steelmaking, direct rolling following continuous casting process and direct quenching of plates after hot rolling require further improvement.

Direct processing has also been promoted. In a near future the on-line direct rolling of continuously

Table 1. Number of papers presented by ISIJ members.

\begin{tabular}{c|ccccccccc}
\hline Year & 1950 & 1955 & 1960 & 1965 & 1970 & 1975 & 1976 & 1977 & 1978 \\
\hline $\begin{array}{c}\text { No. of papers } \\
\text { (per 100 members) }\end{array}$ & 3.36 & 4.08 & 4.20 & 4.03 & 5.34 & 7.90 & 9.01 & 9.86 & 10.58 \\
\hline
\end{tabular}


cast steel will be developed to enable rolling slabs of solid and liquid coexisting state.

In addition, production of powder from molten steel and high alloy steel through powder metallurgy as well as combining of the two processes may become practically applicable in the future.

\section{Metallurgical Science to Make Best Use of Process}

\section{Function}

Two types of metallurgical approach can be considered in this regard. First approach aims at effective operation of refining unit process by combining emphasis on secondary refining such as ladle refining technology or vacuum refining technology. Progress in this aspect is truly looked forward.

The second approach consists of systematic combination of casting, rolling and heat treatment for improvement of quality of steel products by utilizing metallurgical analysis of these processes. Controlled rolling for improved strength and toughness of steel for line pipe has been established as a practically operable method. Further advancement in processing and heat treatment technology is desirable.

\section{Terotechnology}

This is an approach to find the most economical way of operation through comprehensive analysis of effective utilization of facilities, operation rate from the time of installation through termination, maintenance and other relevant factors. Development of facilities diagnosis technology to judge soundness of facilities in operation or to detect existance and absence of defects and facilities life estimation technology to determine the repairing time and life of equipment with defects is an important task to achieve cost reduction.

From this viewpoint, it is desirable to develop tribology to handle wear, friction, and lubrication as well as science of material strength to consider failure and fracture and other properties of material at operation conditions including fatigue, creep, delayed fracture and corrosion crack.

\section{Review from the Perspective of the Users of Steel Products}

Modern iron and steel technology was developed in pursuit of larger, faster and more effective facilities. This pursuit, however, began to show negative effects in unexpected fields such as environmental problems and problems of resources supply and safety. There rose the need to reexamine the technological development policy and reevaluate secondary effects of the technology developed under such policy. At the same time there began to appear change in demands for steel products. Therefore, in order to decide the course of the development of steel products, following factors should be taken into consideration.

\section{Improvement in Reliability}

Demands for reliable steel as component materials of machinery and structure are expected to grow more as the concern for safety of machinery and structure is growing. To satisfy such demands, it will be necessary to guarantee the uniform good quality of the steel products. Considering this requirement, fol- lowing researches are important:

1) Item check of quality (particularly non-destructive continuous measurement of properties during production processes)

2) Non-destructive continuous measurement of non-metallic inclusions and internal or external flaws

3) Establishment of qualitative evaluation method for tolerance limit of defects

4) Establishment of evaluation standard for strength in operating condition including fatigue fracture, delayed fracture and corrosion crack evaluation.

\section{Improvement in Workability}

In order to meet the expected shortage of skilled labor following researches should be made.

1) Comprehensive development of steel with superior weldability, welding method, and welding equipment

2) Comprehensive development in forming technology covering improvement in formability of cold forged steel and sheets, forming method, and forming equipment

3) Development of steel with superior machinability, promotion of automation of processing machinery and development of machining tools

\section{New Material Considering Users' Needs}

Although it is difficult to estimate what kind of new materials will be developed in the future, some examples are presented below.

(1) Maraging steel:

Having low yield point at the quenched state, this steel has good formability even in cold forming and machinability and weldability. Aging treatment following through processing will give extra strength. Accelerated aging (AA) plate is one of this type because its yield point increases with such a lower processing temperature as dehydration of paint after forming.

\section{(2) TRIP steel:}

It is well known that transformation induces excellent plastic deformation. It is, therefore, important to study the deformation characteristics under martensitic transformation.

\section{(3) Hadfield steel}

Once deformation occurs, transformation proceeds and intensive hardening commences. At such portion as receiving impact or load repeatedly, the hardening increases giving excellent friction resistance.

(4) Memory alloy:

Plastic deformation is provided at the temperature below transformation temperature. When the temperature is raised above the transformation point, the original shape recovers. Nitinol, the alloy made of nickel and titanium is well-known.

\section{Review for Economic Use of Irrecoverable Resources}

(1) Utilization of hitherto unused resources:

On time after the war, some researchers tried to utilize laterite ores containing low quality nickel chromium. At that time the attempt did not prove 
the method to be economically practical. Nevertheless, it is worth examining possibilities of this kind of research from time to time under current economy.

(2) Utilization of high entropy energy:

This research should be promoted as a national project.

(3) Development and disemination of corrosion resistance technology:

Its necessity is so widely recognized that detailed explanation is omitted here.

\section{Review from the Recycling Point of View}

With respect to recycling, it is necessary to reorganize technology from total engineering system viewpoint. Under such study, a system should be found to select materials so as to allow their recovery at easy form through disassembling of unused machinery or aged structure for re-processing and assembling.

Until establishment of such system, following measures are proposed.

(1) Improvement in purity and standardization of composition:

Components should be restricted in number as much as possible and mechanical properties should be created through heat treatment and processing. This method has been applied to galvanized sheet for cans for foods.

(2) Enforcement of standardization of steel products:

In this effort simple composition, standardization of shape and size of steel products and standardization of simple parts should be included, also.

(3) Promotion of casset type assembly and unit assembly of mechanical parts for easy replacement to meet deterioration of properties:

This will contribute for improvement in reliability.

\section{Others}

(1) Environmental measures:

Many efforts have been made in this regard, but further efforts to create adequate environments on the basis of ecology are required.

(2) Introduction of life science method

This is a field which requires much time before we see its flourish but we should show continuous concern over its development. For example, when a creature composes materials necessary for maintenance of its life, it does not generate such material excessively but do so sufficiently according to its require- ment. If material $\mathrm{A}$ is not required at a given time the activities are suspended at Stage B, one or two processes preceding Stage A, while material B is transferred to another required material C. Nature shows economic systems in various life patterns.

Looking at the structure of living creatures, many interesting fact are found which are useful for the researchers of iron and steel. One cannot but admire the well-planned and well-linked system in nature. The preciseness of energy utilization system is one of such examples.

\section{Postscript}

This paper is prepared for Centennial Anniversary of The Japan Federation of Engineering Societies and presents the recent history and future perspectives on iron and steel technology in Japan. Mr. Shintaro Tabata, Executive Director of ISIJ, and many others have rendered me warm assistance throughout my inquiries on their opinions. My appreciation is extended to the Secretariat of ISIJ for their cooperation in finding reference materials, also.

\section{REFERENCES}

1) Tetsu-to-Hagané, 61 (1975), No. 5, 60th Anniversary Issue on Progress in The Science and Technology of Iron and Steel in Japan, 443.

2) S. Tabata: Personal correspondence.

3) S. Watanabe: Hints for Future Technology, Blue Books, Kodansha, Tokyo, (1976).

4) K. Iida: Predecessors in Technology and Thoughts, Toyo Keizai Shimpo-sha, (1976).

5) S. Mizushima: Personal correspondence.

6) e.g., IISI Profection '82, (1972); Industrial Structure Investigation Commission: Iron and Steel Industry of 1970's and Policy, (1973);

ECE: Estimated Iron Consumption, Production and Exports for 1985 and Projection of 1990, (1975).

7) Textbook for the 38th Nishiyama Memorial Lecture, ISIJ, (1976):

T. Umino: "Future of Industrial Structure of Japan ";

K. Sanbongi: "Future of Refining Technology";

T. Okamoto: "Future of Plastic Processing ";

K. Horikawa: "Future of Iron and Steel Technology";

T. Kono: " Future of Japanese Iron and Steel Technology and Requirements".

8) T. Kono: "Future of Iron and Steel Industry and Requirements ", Tetsu-to-Hagané, 63 (1977), 154.

9) S. Nagashima: "Direction of Iron and Steel Research", Tetsu-to-Hagané, 64 (1978), 165. 